\title{
A Rare Presentation of Hydatid Cyst: A Case with Radial Bone Involvement
}

\author{
Kist Hidatiğin Nadir Bir Prezentasyonu: Radyal Kemik Tutulumlu Bir \\ Olgu
}

(D) Fatih Bağcıer ${ }^{1}$, (1) Fatih Hakan Tufanoğlu²

${ }^{1}$ Kars State Hospital, Clinic of Physical Medicine and Rehabilitation, Kars, Turkey

${ }^{2}$ Kars State Hospital, Clinic of Radiology, Kars, Turkey

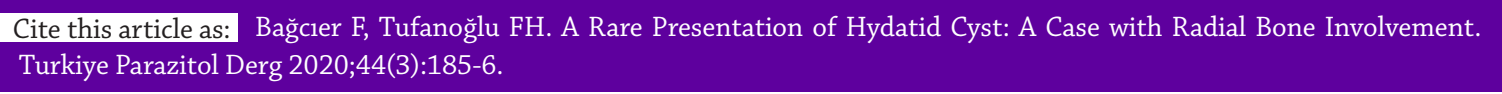

\section{Dear Editor,}

Twenty six-years old female patient has applied to our clinic complaining from pain in her left elbow area. While she had no trauma, she has had pain for several weeks, and swelling has started. Her pain was mechanical in nature. In physical examination, she had pain that was felt with palpation near to left elbow joint in radius proximal area. No sensory and motor deficit was detected. Direct graphy revealed a lytic lesion on elbow area at proximal radial diaphyseal level and medullary location, causing expansion in the bone and thinning in cortex (Figure 1). Computed tomography also revealed a lytic lesion at medullary location in proximal radial diaphyseal area that caused a bow-like appearance in inner tabula and cortical thinning, and slightly expanded the bone (Figure 2). In axial sections, there was a lesion with a thin septa at proximal radial diaphyseal area and central-medullary location with a significant hyperintense signal in proton weighted sequence, causing destruction at anterior cortex and overflowing outside the bone. In the magnetic resonance imaging requested to show possible soft tissue involvement in the area, adjacent to lesion, an edematous signal change was observed in the bone marrow and soft tissues. After surgery was performed on the mass, biopsy of the sample was reported as cyst hydatid. Albendazole $400 \mathrm{mg}$ / day treatment was administered from 1 month before the surgery until postoperative 6 . month. No relapse was determined in the follow-up of the patient in our clinic.

Cyst hydatid disease, which is caused by E. granulosus, is a common zoonosis (1). Bone involvement is around
$0.5 \%-4 \%$. While it is most commonly observed in vertebral (30\%-50\%) and pelvic bones (15\%), it can be observed in long bones such as femur, tibia and humerus (2). The cyst shows a slow development in the bone. The infection is generally acquired in childhood; but its clinical appearance may be delayed until adulthood since incubation period is longer than ten years (3). Therefore, it shows an asymptomatic course for a long time. Secondary infection gives symptoms after fractures or pressure on neighboring neuromuscular structures. The most common clinical symptom is pathologic fracture due to cortical thinning (4). Different from literature, the first symptom in

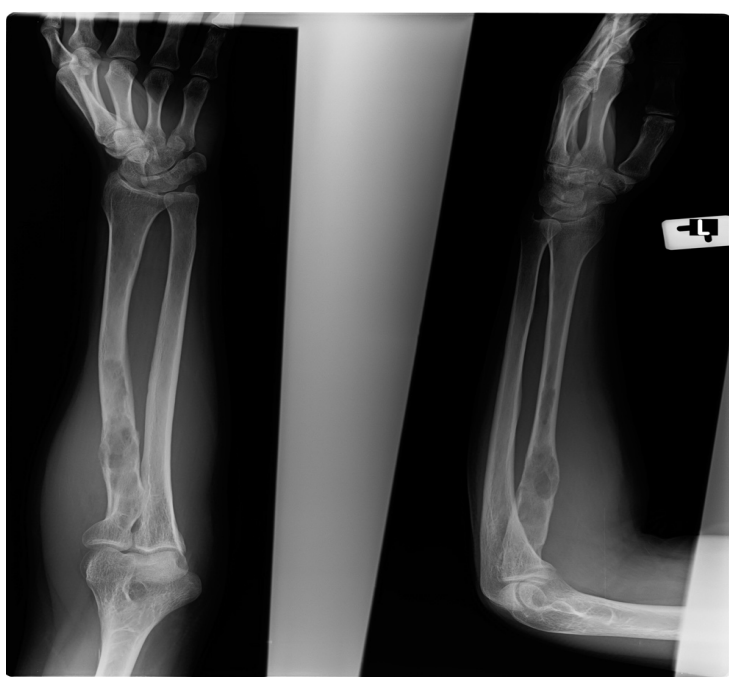

Figure 1. A lytic lesion on elbow area at proximal radial diaphyseal level and medullary location, causing expansion in the bone and thinning in cortex 


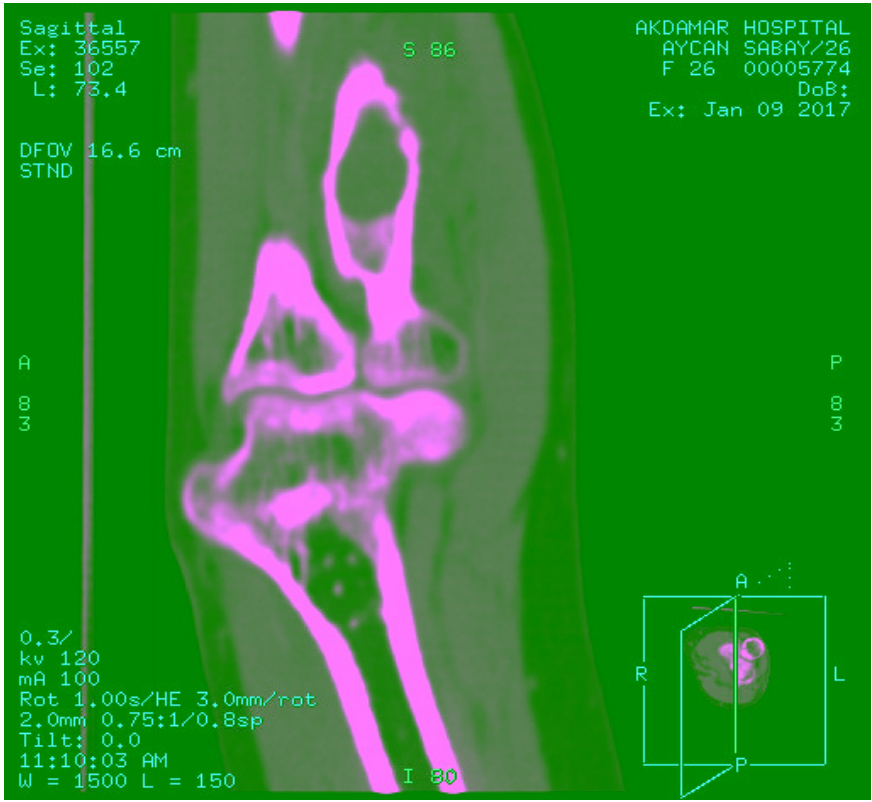

Figure 2. A lytic lesion at medullary location in proximal radial diaphyseal area that caused a bow-like appearance in inner tabula and cortical thinning, and slightly expanded the bone

our case was pain that was mechanical in nature. Among 16 cyst hydatid cases with bone involvement that was reported by Booz (5) in Kuwait, pathological fracture was determined as the first symptom in 9 cases (56\%). Only one cyst hydatid case has been reported in literature with radial involvement similar to our case. In this case, there was involvement in lower one-third of radius. The patient applied to us complaining from local pain as in our case (6).

For diagnosis, a synthesis of clinical findings, laboratory tests and radiological examinations is required, along with medical history. Surgical excision and histopathological examination are required for definitive diagnosis (6). Tuberculosis osteomyelitis, fibrous dysplasia, simple bone cyst and bone tumors should be considered in differential diagnosis. Direct radiographic examination did not give specific results. Computed tomography and magnetic resonance imaging methods are more beneficial $(2,3)$. It was observed that the sensitivity of serological methods was between $25 \%-56 \%$ for bone involvement. No high values were determined in the serological tests of our patient for cyst hydatid diagnosis. Preoperative diagnosis could be determined in only two cases of the four operated bone hydatidosis cases reported by Booz (5). Diagnosis was determined with postoperative biopsy in our case. Surgical treatment alone in hydatid bone cysts may not be successful due to the difficulty of total excision, and it may increase the risk of spreading. For this reason, albendazole treatment (one course before the operation and six courses after the operation) is more successful (2). The mentioned preoperative and postoperative protocol was applied in our case, and the patient is still under follow-up. In conclusion, while hydatid bone cysts are rare, they should be included in differential diagnosis in patients applying with treatment resistant musculoskeletal pain.

Keywords: Cysct hydatic, radius bone, surgery excision

Anahtar Kelimeler: Kist hidatik, radius bone, cerrahi eksizyon

\section{* Ethics}

Peer-review: Externally and internally peer-reviewed.

\section{* Authorship Contributions}

Surgical and Medical Practices: F.B., F.H.T., Concept: F.B., Design: F.H.T., Data Collection or Processing: F.B., Analysis or Interpretation: F.B., Literature Search: F.H.T., Writing: F.B.

Conflict of Interest: No conflict of interest was declared by the authors.

Financial Disclosure: The authors declared that this study received no financial support.

\section{REFERENCES}

1. Bağcıer F, Onaç O, Melikoglu MA. Hydatid cyst presenting with mass that localized in the cruris region. Türkiye Parazitoloji Derg 2016: 40: 54-5.

2. Parola P, Mathieu D, Panuel M. Diagnosis: hydatid bone disease (cystic echinococcosis). Clin Infect Dis 2000; 31: 543-4.

3. Pirhan Y, Kurt N. Bone hydatid cyst disease. Dicle Tip Dergisi 2017; 44: 401-4.

4. Reddy IV, Kumar AA, Samorekar B, Babu BA, Mettu AK. Complicated hydatid cyst of ulna-a rare case report. J Clin Diagn Res 2017; 11: RD01-3.

5. Booz MY. The value of plain film findings in hydatid disease of bone. Clin Radiol 1993; 47: 265-8.

6. Mondal SK, Sengupta SG. Hydatid cyst of radial bone. J Nepal Med Assoc 2009; 48: 321-3. 